\title{
高质量钻钛矿单晶 $\mathrm{CH}_{3} \mathrm{NH}_{3} \mathrm{PbI}_{3}$ 研究进展
}

\author{
楚增勇，李高林，蒋振华，王春华 \\ (国防科技大学文理学院, 长沙 410073)
}

摘 要: 有机-无机钙钛矿材料因为具有光谱吸收范围宽、缺陷密度低、载流子复合率低等非常优良的光电性能吸 引了广泛关注, 掀起了钙钛矿材料研究热潮。近年来杂化钙钛矿型太阳能电池发展迅速, 光电转化效率目前已达到 $22.1 \%$, 展现出极大的应用潜力。与多晶薄膜相比, 单晶具有极低的缺陷密度和极少的界面缺陷。多个课题组成功 培养出大尺寸钙钛矿单晶, 发现钙钛矿单晶材料具有比其他薄膜多晶材料更好的光响应特性, 是设计制备光伏器 件的理想材料。在各类钙钛矿材料中, $\mathrm{CH}_{3} \mathrm{NH}_{3} \mathrm{PbI}_{3}$ 是研究和应用最广泛的一类钙钛矿材料。本文主要针对近年来 $\mathrm{CH}_{3} \mathrm{NH}_{3} \mathrm{PbI}_{3}$ 单晶材料的研究制备进行综述, 介绍了 $\mathrm{CH}_{3} \mathrm{NH}_{3} \mathrm{PbI}_{3}$ 单晶材料的结构及性能, 重点总结了 $\mathrm{CH}_{3} \mathrm{NH}_{3} \mathrm{PbI}_{3}$ 单晶材料生长制备方法和应用, 并对其发展趋势进行了展望。

关 键 词: 钲钛矿; 单晶; $\mathrm{CH}_{3} \mathrm{NH}_{3} \mathrm{PbI}_{3}$; 光电性能; 综述

中图分类号: O782 文献标识码: A

\section{Recent Progress in High-quality Perovskite $\mathrm{CH}_{3} \mathrm{NH}_{3} \mathrm{PbI}_{3}$ Single Crystal}

\author{
CHU Zeng-Yong, LI Gao-Lin, JIANG Zhen-Hua, WANG Chun-Hua
}

(College of Liberal Arts and Sciences, National University of Defense Technology, Changsha 410073, China)

\begin{abstract}
Organic-inorganic hybrid halide perovskites have attracted a huge amount of research interest and arised new research upsurge due to its broad absorption range, low trap density, low carrier recombination, and other excellent optoelectronic properties. Perovskite solar cells have shown great potential for application with maximum power conversion efficiencies evolving from $3.8 \%$ to $22.1 \%$ in just a few years. Single crystal has extremely low defect density and minimal interface defect than polycrystalline materials. Several research groups successfully cultivated large-sized perovskite single crystals, finding that perovskite single crystal is an ideal material for design and fabrication of photovoltaic devices for better light-response than polycrystalline and thin-film materials. Among all kinds of perovskite materials, $\mathrm{CH}_{3} \mathrm{NH}_{3} \mathrm{PbI}_{3}$ is one of the most widely studied and applied perovskite materials. This paper reviews the study of $\mathrm{CH}_{3} \mathrm{NH}_{3} \mathrm{PbI}_{3}$ single crystal recently, introducing its structure and superior characteristics. Particularly, growth methods and applications of perovskite single crystals are highlighted. Finally, the development trend of perovskite single crystals is prospected.
\end{abstract}

Key words: hybrid halide perovskite; single crystal; $\mathrm{CH}_{3} \mathrm{NH}_{3} \mathrm{PbI}_{3}$; optoelectronic property; review

随着经济社会的不断发展，人类社会对能源的 需求量越来越大; 然而目前主要依赖的化石能源基 本不可再生, 而且化石能源的大量开采使用已经给
自然环境造成巨大破坏，经济社会发展面临巨大能 源压力，因此寻找清洁无污染的新能源已成为当务 之急。太阳能作为分布最广泛的清洁能源, 储量巨 
大，利用清洁无污染的光伏发电技术直接将太阳能 转化为电能用于社会生产生活缓解能源压力的需求 十分迫切。自上世纪五十年代以来, 太阳能电池技 术发展迅猛, 各种各样的太阳能电池相继问世, 单 晶硅太阳能电池、多晶硅太阳能电池、染料敏化太 阳能电池、有机光伏太阳能电池、钲钛矿太阳能电 池等。如图 1 所示, 钙钛矿太阳能电池作为其中一 种新兴的太阳能电池, 自 2009 年首次报道以来, 经 过短短几年时间的发展, 其光电转化效率就从首次 报道的 $3.8 \%^{[1]}$ 提高到目前的 $22.1 \%^{[2]}$, 发展速度超 过以往任何一种太阳能电池, 展现出极大的市场应 用潜力, 一跃成为光电领域最有发展潜力的研究 热点。

\section{1 钙钛矿晶体结构}

本文所讨论的钙钛矿材料是一种有机一无机杂 化钙钛矿半导体材料一一基胺-金属-卤素系钙钛 矿, 最早由 Weber ${ }^{[4]}$ 报道, 其晶体结构如图 2 所示,

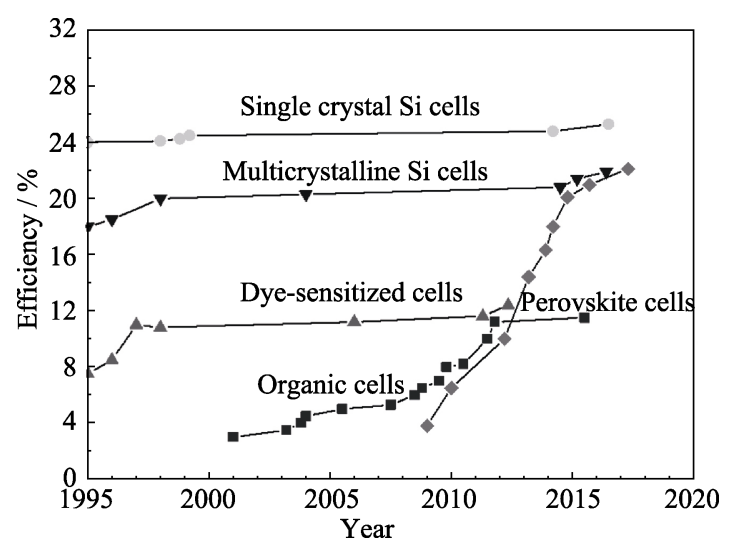

图 1 太阳能电池光电转化效率发展 ${ }^{[3]}$

Fig. 1 The development of solar cells photoelectric conversion efficiency ${ }^{[3]}$

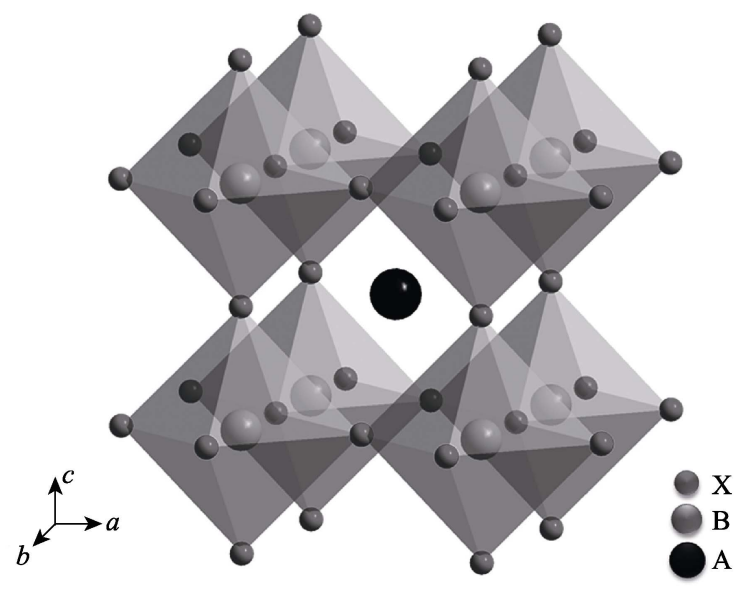

图 2 钲钛矿晶体结构 ${ }^{[5]}$

Fig. 2 Drawing of crystal structure of hybrid halide perovskite ${ }^{[5]}$
典型分子结构式为 $\mathrm{ABX}_{3}$, 属于立方晶系或四方晶 系, 其中 $\mathrm{A}$ 一般为 $\mathrm{CH}_{3} \mathrm{NH}_{3}{ }^{+}$或 $\mathrm{CH}\left(\mathrm{NH}_{2}\right)_{2}{ }^{+}, \mathrm{B}$ 为 $\mathrm{Pb}^{2+}$, $\mathrm{X}$ 为卤素负离子 $\left(\mathrm{Cl}^{-}, \mathrm{Br}^{-}\right.$或 $\left.\mathrm{I}^{-}\right)$。

在杂化钙钣矿晶体中, 一个 $\mathrm{Pb}^{2+}$ 周围配位 6 个 卤素负离子构成 $\left[\mathrm{PbX}_{6}\right]^{4-}$ 八面体, $\left[\mathrm{PbX}_{6}\right]^{4-}$ 八面体又 与周围 $\left[\mathrm{PbX}_{6}\right]^{4-}$ 八面体公用所有顶点构成晶体三维 框架, $\mathrm{CH}_{3} \mathrm{NH}_{3}{ }^{+}$或 $\mathrm{CH}\left(\mathrm{NH}_{2}\right)^{2+}$ 则填充在 $\left[\mathrm{PbX}_{6}\right]^{4-}$ 八面 体形成的空隙中，在整个钙钛矿晶体中有机组分与 无机组分相互掺杂，实现了有机组分和无机组分的 在分子层面的嵌入杂化。

通常情况下可以用容忍因子 $t$ 来衡量钙钛矿晶 体的稳定性, 容忍因子 $t$ 计算公式如下:

$$
t=\frac{\left(r_{\mathrm{A}}+r_{\mathrm{X}}\right)}{\sqrt{2}\left(r_{\mathrm{B}}+r_{\mathrm{X}}\right)}
$$

$r_{\mathrm{A}} 、 r_{\mathrm{B}} 、 r_{\mathrm{X}}$ 分别为钙钛矿晶体中相应组分的离子半 径。一般来说，容忍因子 $t$ 在 $0.8 \sim 1.0$ 之间时，晶体 结构相对比较稳定, 由上式可得 $\mathrm{CH}_{3} \mathrm{NH}_{3} \mathrm{PbI}_{3}$ 的容 忍因子为 $\sim 0.8345\left(r_{\mathrm{Pb}^{2+}}{ }^{2+} 0.119 \mathrm{~nm}^{[6]}, r_{\mathrm{I}}^{-}=0.220 \mathrm{~nm}^{[6]}\right.$,

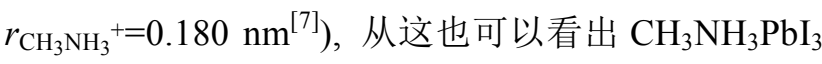
材料晶体结构稳定性一般。当然需要指出的是容忍 因子并不是衡量钙钛矿晶体稳定性的唯一标准。

特殊的晶体结构使得钙钛矿材料具有一些特殊 的材料特性，比如低载流子复合率、宽吸收光谱、 高载流子迁移率和低缺陷密度等; 也正是因为钙 钛矿材料具有比较好的光伏性能，几年时间内基 于钙钛矿材料的光电器件有了飞速发展, 其中 $\mathrm{CH}_{3} \mathrm{NH}_{3} \mathrm{PbI}_{3}$ 的各类材料是应用最广泛的钙钛矿材 料。在 $\mathrm{CH}_{3} \mathrm{NH}_{3} \mathrm{PbI}_{3}$ 各种尺寸和形貌的材料中, 单晶 材料又以更低的晶体缺陷密度, 成为最有应用潜力 和研究价值的杂化钙钛矿材料; 大尺寸单晶体也是 研究材料本身光电特性的最佳平台, 有利于加深对 材料性质和光转换机理的探索理解, 甚至人工设计 出性能更好的光电材料。因此在这里主要介绍 $\mathrm{CH}_{3} \mathrm{NH}_{3} \mathrm{PbI}_{3}$ 单晶材料研究进展, 希望能吸引更多 的研究者关注钙钛矿单晶材料, 进一步促进钙钛矿 光电器件的发展。

\section{$2 \mathrm{CH}_{3} \mathrm{NH}_{3} \mathrm{PbI}_{3}$ 单晶的性能}

钙钛矿太阳电池展现出了很大的发展潜力, 基 于不同形貌钙钛矿材料制备的太阳能电池迭出不穷, 光电转化效率也有了很大提升 ${ }^{[8-20]}$ 。国内外多个课 题组在新型电池结构 ${ }^{[10-13]}$ 、电池稳定性 ${ }^{[16-17]}$ 和界面 修饰 ${ }^{[18-20]}$ 等方面已取得重要突破，但是钙钛矿太阳 能电池在水氧环境下极易分解仍是限制其发展应用 
的主要问题之一; 另外钙钛矿材料的光电转化机 理、界面电荷传输转移等特性尚不完全清楚也限制 了对材料本身和电池设计的理解。

通常情况下大尺寸块状单晶的稳定性要比薄膜 多晶材料好得多, 基于 $\mathrm{CH}_{3} \mathrm{NH}_{3} \mathrm{PbI}_{3}$ 单晶材料制备 的太阳能电池有望展现出更好的稳定性; 除此之外, 大尺寸高质量的 $\mathrm{CH}_{3} \mathrm{NH}_{3} \mathrm{PbI}_{3}$ 单晶材料通常展现出 更优的光电性能; 更宽的光谱吸收、更长的载流子 迁移距离、更低的缺陷密度等, 是研究钻钛矿材料 性质、结构和光电转换机理的理想材料 ${ }^{[21-24]}$ 。

$\mathrm{CH}_{3} \mathrm{NH}_{3} \mathrm{PbI}_{3}$ 晶体材料最早由 $\mathrm{Weber}^{[4]}$ 于 1978 年报道, 1987 年 Poglitsch 和 Weber 成功制备出 $\mathrm{CH}_{3} \mathrm{NH}_{3} \mathrm{PbX}_{3}\left(\mathrm{X}=\mathrm{Cl}^{-}, \mathrm{Br}^{-}, \mathrm{I}^{-}\right)$小晶体并测试了其晶体 结构参数及晶相转变温度 ${ }^{[25]}$ 。2009 年, Miyasaka 等 ${ }^{[1]}$ 首次将 $\mathrm{CH}_{3} \mathrm{NH}_{3} \mathrm{PbI}_{3}$ 用作太阳能电池吸光材料并取 得 $3.8 \%$ 的光电转换效率。随后众多研究者开始研究 $\mathrm{CH}_{3} \mathrm{NH}_{3} \mathrm{PbX}_{3}\left(\mathrm{X}=\mathrm{Cl}^{-}, \mathrm{Br}^{-}, \mathrm{I}^{-}\right)$材料在光电领域的应用,

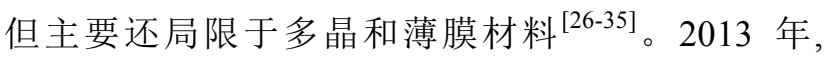
Baikie 课题组 ${ }^{[26]}$ 和 Kanatzidis 课题组 ${ }^{[36]}$ 首次报道成 功制备 $\mathrm{CH}_{3} \mathrm{NH}_{3} \mathrm{PbI}_{3}$ 多晶材料并测试了其光电性能。 2014 年 Pisoni 等 ${ }^{[37]}$ 注意到 $\mathrm{CH}_{3} \mathrm{NH}_{3} \mathrm{PbI}_{3}$ 多晶和单晶 材料导热性能存在明显差异。紧接着, Tao 课题组 ${ }^{[38]}$ 第一次成功制备出厘米尺寸钙钛矿单晶并发现大尺 寸 $\mathrm{CH}_{3} \mathrm{NH}_{3} \mathrm{PbI}_{3}$ 单晶的光电性能及热稳定性要明显 好于多晶和薄膜材料。随后两年多的时间里多个课 题组陆续采用不同方法成功制备出高质量大尺寸 $\mathrm{CH}_{3} \mathrm{NH}_{3} \mathrm{PbI}_{3}$ 单晶 ${ }^{[39-45]}$, 其中 Liu 课题组 ${ }^{[43]}$ 通过溶液 升温法成功制备出尺寸为 $71 \mathrm{~mm} \times 54 \mathrm{~mm} \times 39 \mathrm{~mm}$ 的 $\mathrm{CH}_{3} \mathrm{NH}_{3} \mathrm{PbI}_{3}$ 单晶, 是当时已知的最大钙钣矿单晶。

相对于其他类型的钙钛矿材料, 单晶一般具有 更宽的光谱吸收范围 ${ }^{[38]}$ 。 $\mathrm{CH}_{3} \mathrm{NH}_{3} \mathrm{PbI}_{3}$ 单晶材料的吸 收截止波长一般在 $830 \sim 850 \mathrm{~nm}$ 之间, 而薄膜材料
吸收截止波长通常只有不到 $800 \mathrm{~nm}$ ，单晶材料的光 谱吸收范围比薄膜材料拓宽了至少 $30 \mathrm{~nm}$, 使得基 于 $\mathrm{CH}_{3} \mathrm{NH}_{3} \mathrm{PbI}_{3}$ 钙钛矿单晶材料制备的太阳能电池短 路电流密度从 $27.5 \%$ 提高到 $33.0 \%{ }^{[40]}$, 单晶和薄膜两 种材料制备的太阳能电池的外量子效率 $\mathrm{EQE}$ 也印 证了这一点。如图 3(a) 所示, 在测得的 $\mathrm{CH}_{3} \mathrm{NH}_{3} \mathrm{PbI}_{3}$ 单晶紫外-可见反射光谱基础上, 根据 Tauc 公式(1) 和 Kubelka-Munk 公式(2)可得 $\mathrm{CH}_{3} \mathrm{NH}_{3} \mathrm{PbI}_{3}$ 单晶的禁 带宽度约为 $1.50 \mathrm{eV}$ (不同制备方法和测试方法略有 差异), 明显低于薄膜和多晶材料禁带宽度 ${ }^{[25]}$ 。

$$
\begin{gathered}
(\alpha h v)=\mathrm{C}\left(h v-E_{\mathrm{g}}\right) \\
F(R \infty)=\frac{(1-R)^{2}}{2 R}=\frac{\alpha}{S}
\end{gathered}
$$

这里 $\alpha$ 为物质吸光系数, 随波长变化而变化; $s$ 为散 射系数, 一般不随波长变化; $R$ 为反射率, $E_{\mathrm{g}}$ 为材料 禁带宽度。

目前为止结晶质量较好的 $\mathrm{CH}_{3} \mathrm{NH}_{3} \mathrm{PbI}_{3}$ 单晶缺 陷密度可以控制在 $10^{-9} \sim 10^{-10} \mathrm{~cm}^{-3[43]}$, 和单晶硅材 料缺陷密度相当, 比多晶材料缺陷密度低 5 个数量 级。晶体内缺陷点可以作为载流子复合中心引起空穴 电子对复合, 降低载流子浓度, 使载流子利用率下 降，载流子对复合时释放的热量容易提高晶格温度, 对器件性能产生影响; 而 $\mathrm{CH}_{3} \mathrm{NH}_{3} \mathrm{PbI}_{3}$ 单晶和多晶材 料在室温下的热导率只有 0.5 和 $0.3 \mathrm{~W} /(\mathrm{m} \cdot \mathrm{K})$, 会阻滞 热量快速扩散 ${ }^{[37]}$, 容易产生机械应力缩短器件寿 命。从材料导热性能和载流子利用率两方面考虑, 尽量寻找缺陷密度小的钙钛矿材料作光吸收层是提 高器件性能的重要基础。

与薄膜多晶材料相比, 钙钛矿单晶材料中电子和 空穴迁移能力更强, 载流子提取效率更高。Dong 等 ${ }^{[00]}$ 通过霍尔效应测得 $\mathrm{CH}_{3} \mathrm{NH}_{3} \mathrm{PbI}_{3}$ 单晶的空穴迁移
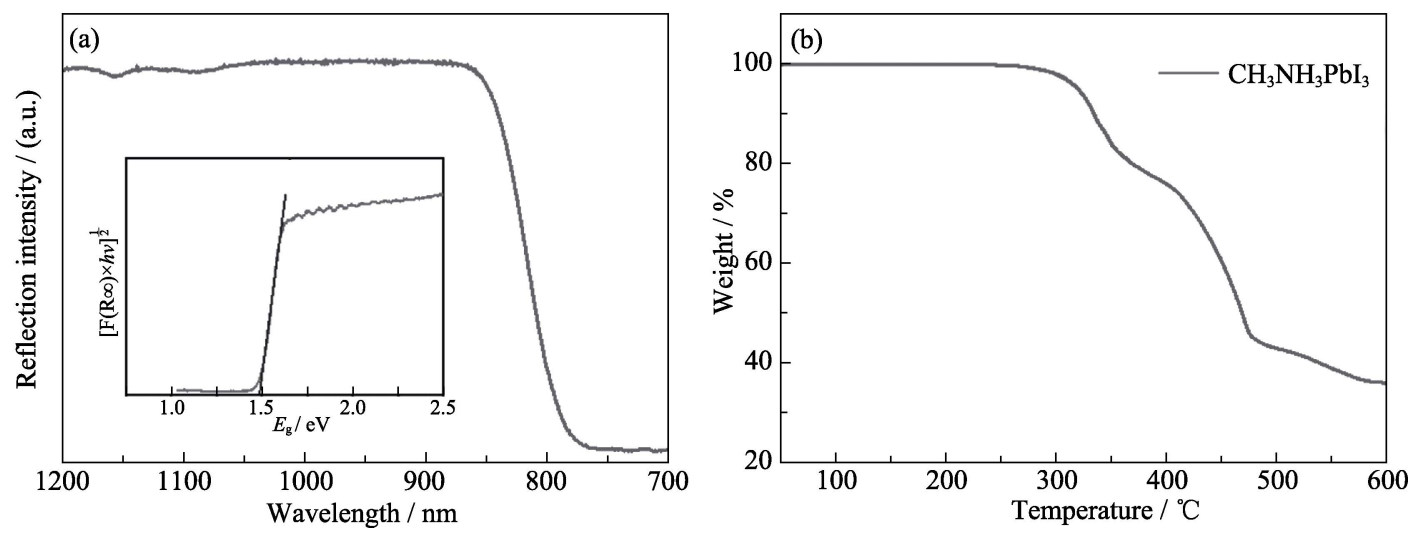

图 $3 \mathrm{CH}_{3} \mathrm{NH}_{3} \mathrm{PbI}_{3}$ 单晶(a)反射光谱及(b)热重曲线 ${ }^{[46]}$

Fig. 3 (a) Reflection spectrum and (b) TGA curve of $\mathrm{CH}_{3} \mathrm{NH}_{3} \mathrm{PbI}_{3}$ single crystal ${ }^{[46]}$ 
率为 $(105 \pm 35) \mathrm{cm}^{2} \cdot \mathrm{V}^{-1} \cdot \mathrm{S}^{-1}$, 电子迁移率可以达到 $(24.8 \pm 4.1) \mathrm{cm}^{2} \cdot \mathrm{V}^{-1} \cdot \mathrm{S}^{-1}$, 是同等条件下多晶 ${ }^{[36]}$ 和薄膜 ${ }^{[47]}$ 材料的数倍。1 太阳光照 $\left(100 \mathrm{~mW} \cdot \mathrm{cm}^{-2}\right)$ 下通过瞬 态光伏(TPV)测得 $\mathrm{CH}_{3} \mathrm{NH}_{3} \mathrm{PbI}_{3}$ 单晶的载流子寿命可 达到 $82 \pm 5 \mu \mathrm{s}$, 载流子扩散距离为 $(175 \pm 25) \mu \mathrm{m}$, 远远 超过多晶和薄膜材料 ${ }^{[40]}$, 因此基于 $\mathrm{CH}_{3} \mathrm{NH}_{3} \mathrm{PbI}_{3}$ 单 晶材料制备的光电器件有望取得更好的光电性能。

钙钛矿单晶材料不仅具有非常好的光电特性, 压电特性和热稳定性也非常不错。Huang 课题组 ${ }^{[48]}$ 发现 $\mathrm{CH}_{3} \mathrm{NH}_{3} \mathrm{PbI}_{3}$ 单晶沿[001]方向具有非常明显的 压电效应, 压电系数可以达到 $2.7 \mathrm{pm} \cdot \mathrm{V}^{-1}$, 而薄膜多 晶材料显然并不具有此特性, 这说明 $\mathrm{CH}_{3} \mathrm{NH}_{3} \mathrm{PbI}_{3}$ 单 晶材料或可用于压电传感器件。从热重图谱(图 3(b)) 可以看出, $\mathrm{CH}_{3} \mathrm{NH}_{3} \mathrm{PbI}_{3}$ 单晶材料可以承受 $250^{\circ} \mathrm{C}$ 的 高温而不分解, 在 300 到 $500^{\circ} \mathrm{C}$ 时逐渐分解失重约 $30 \%, 500$ 到 $700{ }^{\circ} \mathrm{C}$ 进一步分解失重约 $50 \%$ 。除了要考 虑钻钛矿材料的热稳定性, 其在空气和溶剂中的稳 定性也很重要, 实验表明钙钛矿单晶 $\mathrm{CH}_{3} \mathrm{NH}_{3} \mathrm{PbI}_{3}$ 能 在乙醚、丙酮、乙酸乙酯、二氯甲烷(DCM) 和氯苯 (CB) 中稳定存在, 遇水和乙醇易分解, 但过量 $\mathrm{CH}_{3} \mathrm{NH}_{3} \mathrm{I}$ 的存在能有效提高其在水溶液中的稳定 性 ${ }^{[22]}, \mathrm{CH}_{3} \mathrm{NH}_{3} \mathrm{PbI}_{3}$ 单晶不具有主动吸水性, 即使暴 露在空气中也能在一段时间内保持相对较好的稳 定性 ${ }^{[49]}$ 。

多种实验测试结果都表明, 正是因为钙钛矿单 晶具有极低的缺陷密度, $\mathrm{CH}_{3} \mathrm{NH}_{3} \mathrm{PbI}_{3}$ 单晶材料才具 有比薄膜和多晶更好的光电性能和稳定性 ${ }^{[50-51]}$; 研 究制备高结晶质量低缺陷密度的 $\mathrm{CH}_{3} \mathrm{NH}_{3} \mathrm{PbI}_{3}$ 钲钛 矿单晶材料是提高钙钛矿太阳能电池光电转换效率 和稳定性的有效手段, 是未来突破钙钛矿太阳能电 池发展限制的可行选择。

\section{$3 \mathrm{CH}_{3} \mathrm{NH}_{3} \mathrm{PbI}_{3}$ 单晶的制备方法}

低缺陷密度的高质量 $\mathrm{CH}_{3} \mathrm{NH}_{3} \mathrm{PbI}_{3}$ 单晶在光电 转换、激光发光、光电探测、高能射线和带电粒子 探测等领域具有重要应用, 但 $\mathrm{CH}_{3} \mathrm{NH}_{3} \mathrm{PbI}_{3}$ 结晶性 相对较差, 是最难生长培养的钙钛矿单晶之一, 很 容易受生长条件和生长速度的影响 ${ }^{[52]}$ 。单晶性能又 很容易受晶体结晶质量影响, 结晶质量越高材料性 能越好。一般来说, 晶体生长速度越慢结晶质量越 高, 然而生长速度太慢显然是应该尽量避免的, 迫 切需要寻找一种方法既能够快速高效地生长大尺寸 $\mathrm{CH}_{3} \mathrm{NH}_{3} \mathrm{PbI}_{3}$ 单晶又能保证其较高的结晶质量。根据 文献报道, 目前关于 $\mathrm{CH}_{3} \mathrm{NH}_{3} \mathrm{PbI}_{3}$ 单晶的生长培养 主要有三类比较典型的方法; 溶液降温结晶
(Solution Temperature-Lowering Crystallization, STL)、 溶液升温结晶(Inverse Temperature Crystallization, ITC) 和溶剂辅助结晶 (Solvent-Assisted Crystallization, SAC)。

\section{1 溶液降温结晶(STL)}

溶液降温结晶是一种比较常用的单晶生长方法, 利用溶质在较高温度和较低温度时的溶解度差, 使 在较高温度下达到饱和或近似饱和浓度的溶液在降 温过程中结晶。在这个过程中, 温度、浓度、纯度 等条件控制的精细程度会很大程度上影响生长单晶 的质量和尺寸, 要得到大尺寸的钙钠矿单晶一般要 在溶液中引入籽晶多次重复降温结晶过程, 比较常 见的有底部籽晶法(Bottom-Seeded Solution Growth, BSSG)和顶部籽晶法(Top-Seeded Solution Growth, TSSG)。

\subsection{1 底部籽晶法(BSSG)}

Weber 和 Poglitsch 等 ${ }^{[25]}$ 第一次通过氢碘酸溶液 降温法制备出 $\mathrm{CH}_{3} \mathrm{NH}_{3} \mathrm{PbI}_{3}$ 晶体, 按摩尔比将醋酸 铅和甲胺水溶液在 $100^{\circ} \mathrm{C}$ 氢碘酸溶液里混合, 直接冷 却降温后得到 $\mathrm{CH}_{3} \mathrm{NH}_{3} \mathrm{PbI}_{3}$ 小晶体。2014 年, Tao 课 题组 ${ }^{[38]}$ 采用类似的方法成功制备出 $10 \mathrm{~mm} \times 10 \mathrm{~mm} \times$ $8 \mathrm{~mm}$ 大小的 $\mathrm{CH}_{3} \mathrm{NH}_{3} \mathrm{PbI}_{3}$ 单晶, 与 Weber 不同的是 Tao 等先用甲胺水溶液和氢碘酸在冰水浴中合成 $\mathrm{CH}_{3} \mathrm{NH}_{3} \mathrm{I}$, 再用氢碘酸作溶剂配制生长溶液并降温 结晶, 选取结晶质量好的 $\mathrm{CH}_{3} \mathrm{NH}_{3} \mathrm{PbI}_{3}$ 小晶体置于 溶液底部作籽晶多次重复降温过程成功制备出首个 厘米级 $\mathrm{CH}_{3} \mathrm{NH}_{3} \mathrm{PbI}_{3}$ 单晶, 如图 4(a)和(b) 所示。实 验证明降温过程中温度不能低于 $40^{\circ} \mathrm{C}$, 否则会有 $\left(\mathrm{CH}_{3} \mathrm{NH}_{3}\right)_{4} \mathrm{PbI}_{6} \cdot 2 \mathrm{H}_{2} \mathrm{O}$ 晶体析出 ${ }^{[53]}$ 。此后, Lian 等 ${ }^{[42]}$ 在此基础上改进了籽晶的放置方式后也成功制备出 厘米级 $\mathrm{CH}_{3} \mathrm{NH}_{3} \mathrm{PbI}_{3}$ 单晶, 如图 4(c)所示, 并在单晶 基础上设计出性能更好的单晶光电探测器。

\subsection{2 顶部籽晶法(TSSG)}

顶部籽晶法在底部籽晶法的基础上改进了籽晶 的放置位置和溶液的物料补充方式，也是利用溶液 在不同温度下饱和浓度差结晶。Huang 课题组 ${ }^{[0]}$ 首 次利用溶液中上下温度梯度和离子对流在单晶硅片 上生长 $\mathrm{CH}_{3} \mathrm{NH}_{3} \mathrm{PbI}_{3}$ 单晶, 选取结晶质量好的小晶 体固定在硅片上作籽晶, 剩余小晶体置于溶液底部 作生长补充材料。如图 4(d) 和 (e) 所示, 利用 $\mathrm{CH}_{3} \mathrm{NH}_{3} \mathrm{PbI}_{3}$ 溶液在不同温度下的溶解度差使硅片 上的籽晶逐渐长大, 最后得到尺寸为 $10 \mathrm{~mm} \times 3 \mathrm{~mm}$ 的 $\mathrm{CH}_{3} \mathrm{NH}_{3} \mathrm{PbI}_{3}$ 单晶。顶部籽晶法一般只需一次性 引入䊏晶和生长物料, 无需多次重复降温, 能较好 地保证晶体在整个生长过程中的稳定性和连续性。 


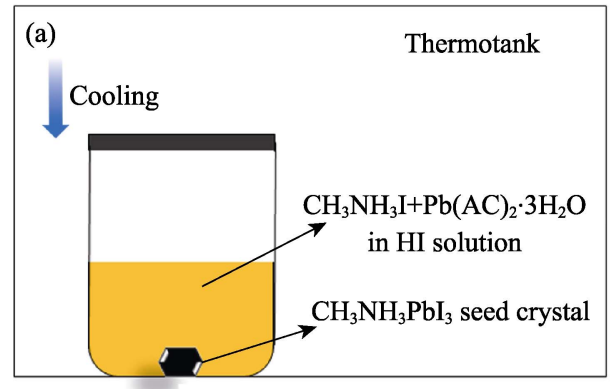

(d)
Silicon substrate

d)
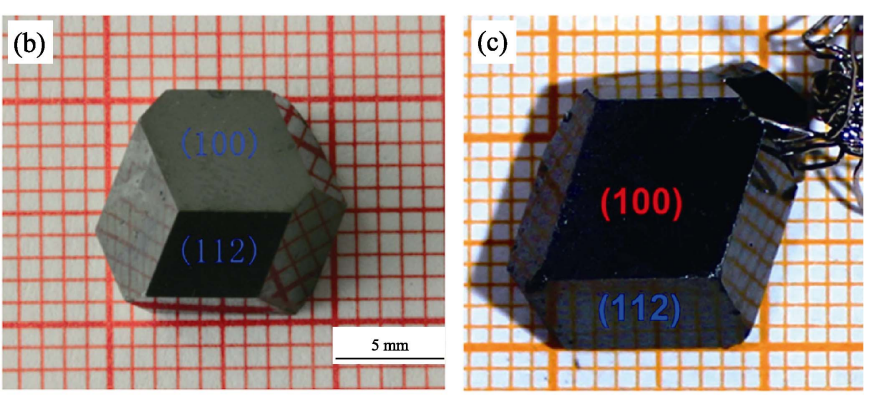

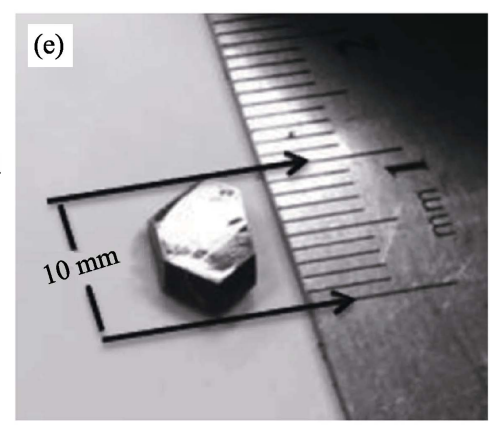

Hot plate

图 4 降温法结晶 (a) (c)底部籽晶法结晶过程及单晶实物照片 ${ }^{[38,42]}$; (d) (e) 顶部籽晶法结晶过程及单晶实物照片 ${ }^{[40]}$

Fig. 4 Schematic diagram of solution temperature-lowering crystallization(STL)

(a)-(c) Crystallization process of BSSG and images of as-prepared $\mathrm{CH}_{3} \mathrm{NH}_{3} \mathrm{PbI}_{3}$ single crystal ${ }^{[38,42]}$;

(d)-(e) Crystallization process of TSSG and image of as-prepared $\mathrm{CH}_{3} \mathrm{NH}_{3} \mathrm{PbI}_{3}$ single crystal ${ }^{[40]}$

\section{2 溶液升温结晶(ITC)}

与上述降温法类似, 升温法也是利用溶质在不 同温度下的溶解度差使溶质结晶析出, 不同的是升 温法利用的是溶质在某种或某类溶剂中随温度升高 而溶解度降低的特性。总的来说升温法和降温法都 是利用溶质在溶液中溶解度随温度变化特性, 任何 条件下达到饱和浓度都是物质结晶的驱动力。

2015 年, $\mathrm{Kadro}$ 等 ${ }^{[4]}$ 首次发现钻铁矿 $\mathrm{CH}_{3} \mathrm{NH}_{3} \mathrm{PbI}_{3}$ 在 $\gamma$-丁内酯(GBL)中的溶解度随温度升高反而降低。 同年 Saidaminov 课题组 ${ }^{[41]}$ 注意到 $\mathrm{CH}_{3} \mathrm{NH}_{3} \mathrm{PbX}_{3}$
$\left(\mathrm{X}=\mathrm{Cl}^{-}, \mathrm{Br}^{-}, \mathrm{I}^{-}\right)$都具有这一特性，并且利用溶液升温 结晶成功生长出高质量钻钣矿单晶, 如图 5(a) (b), 而且实现了晶体形状控制。几乎同时, Liu 课题组 ${ }^{[43]}$ 也利用升温结晶培养出尺寸为 $71 \mathrm{~mm} \times 54 \mathrm{~mm} \times 39 \mathrm{~mm}$ 的 $\mathrm{CH}_{3} \mathrm{NH}_{3} \mathrm{PbI}_{3}$ 单晶, 如图 5(c) 所示, 取得比多晶薄 膜好得多的结晶质量和晶体性能, 目前已知最大的 钙钎矿单晶也是由该课题组用此方法得到的 ${ }^{[55-56]}$ 。 如图 5(d)所示, 溶液升温结晶实现了 $\mathrm{CH}_{3} \mathrm{NH}_{3} \mathrm{PbI}_{3}$ 单晶的快速生长, 在几小时内就可以实现毫米级甚 至厘米级的单晶生长, 是快速高效生长大尺寸钻钛 (a)

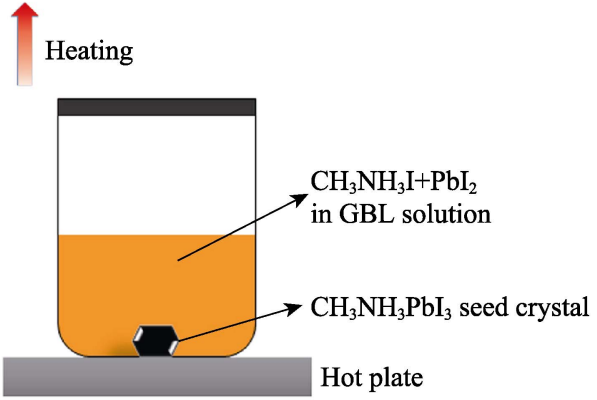

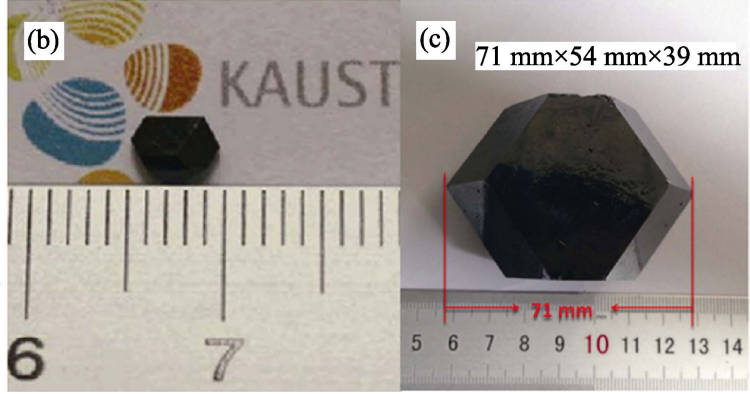

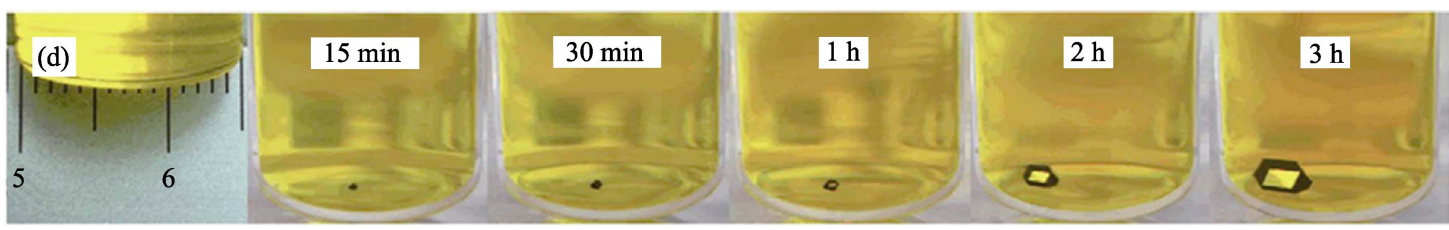

图 5 升温法结晶 (a) (c) 升温结晶法示意图及单晶实物照片 ${ }^{[41,43]}$; (d) 升温结晶溶液中 $\mathrm{CH}_{3} \mathrm{NH}_{3} \mathrm{PbI}_{3}$ 单晶随时间变化的照片 ${ }^{[41]}$

Fig. 5 Schematic diagram of inverse temperature crystallization (ITC)

(a)-(c) Crystallization process of ITC and images of as-prepared $\mathrm{CH}_{3} \mathrm{NH}_{3} \mathrm{PbI}_{3}$ single crystal ${ }^{[41,43]}$;

(d) $\mathrm{CH}_{3} \mathrm{NH}_{3} \mathrm{PbI}_{3}$ crystal growth at different time intervals by ITC $^{[41]}$ 
矿单晶的有效方法 ${ }^{[41]}$ 。

如图 6 所示, Liu 课题组 ${ }^{[57]}$ 随后在溶液升温结晶 的基础上利用空间限域的方法制备出 $\mathrm{CH}_{3} \mathrm{NH}_{3} \mathrm{PbI}_{3}$ 单晶片，通过调节基板之间间隙大小成功实现单晶 片厚度调控获得一系列不同厚度( 150、 330、 670 和 $1440 \mathrm{~nm})$ 的 $\mathrm{CH}_{3} \mathrm{NH}_{3} \mathrm{PbI}_{3}$ 单晶片。为钻钛矿单晶 材料在各种光电器件应用打下基础, 该课题组在 $\mathrm{CH}_{3} \mathrm{NH}_{3} \mathrm{PbI}_{3}$ 单晶片基础上批量制备的光电探测器 也取得非常不错的光电响应效果，与薄膜多晶同类 材料对比测试中, 单晶片都展现出非常好的结晶质 量和性能 ${ }^{[57]}$ 。

\section{3 溶剂辅助结晶(SAC)}

溶剂辅助结晶法又称反溶剂结晶法(Anti-Solvent Crystallization, ASC), 即利用某种反溶剂(负溶剂或 逆溶剂)使溶质从溶液析出晶体的方法, 是培养钙 钛矿 $\mathrm{CH}_{3} \mathrm{NH}_{3} \mathrm{PbI}_{3}$ 单晶最有效的方法之一。目前已 报道的反溶剂有二氯甲烷、乙腈 $(\mathrm{ACN})$ 和氯苯, 基本 原理都是利用某种溶剂改变 $\mathrm{CH}_{3} \mathrm{NH}_{3} \mathrm{PbI}_{3}$ 在 $\gamma$-丁内 酯中溶解度, 使溶质在相对较低温度即可达到饱和 浓度结晶析出, 低温下结晶有利于降低 $\mathrm{CH}_{3} \mathrm{NH}_{3} \mathrm{PbI}_{3}$ 单晶材料载流子复合率实现更好的光电性能 ${ }^{[58]}$ 。

\subsection{1 二氯甲烷辅助结晶}

2014 年, Bakr 等 ${ }^{[39]}$ 首次提出反溶剂辅助钙钛矿 结晶法, 利用二氯甲烷挥发使其缓慢进入晶体生长溶 液, 因为 $\mathrm{CH}_{3} \mathrm{NH}_{3} \mathrm{I}$ 和 $\mathrm{PbI}_{2}$ 完全不溶于二氯甲烷，随 着溶液中二氯甲烷量的增多, 溶质会以 $\mathrm{CH}_{3} \mathrm{NH}_{3} \mathrm{PbI}_{3}$ 形式逐渐结晶析出并长大, 通过调节二氯甲烷的挥

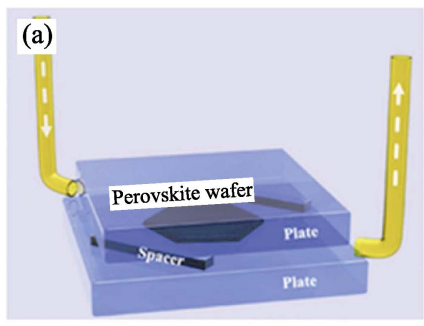

(c)

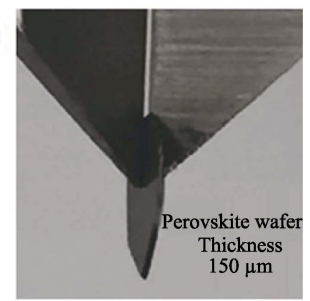

(c)
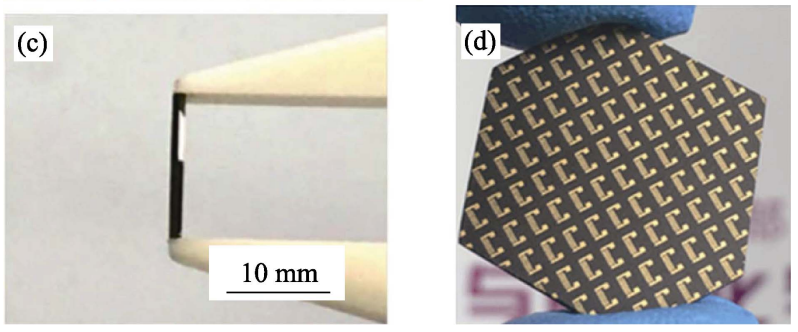

图 6 (a) (c) 空间限域制备 $\mathrm{CH}_{3} \mathrm{NH}_{3} \mathrm{PbI}_{3}$ 单晶片示意图及实 物照片; (d) $\mathrm{CH}_{3} \mathrm{NH}_{3} \mathrm{PbI}_{3}$ 单晶膜批量制备光电探测器 ${ }^{[57]}$

Fig. 6 (a)-(c) Schematic diagram of thinness- and shapecontrolled growth and images of as-prepared $\mathrm{CH}_{3} \mathrm{NH}_{3} \mathrm{PbI}_{3}$ single crystal wafer; (d) Mass photodetectors based on a piece of single $\mathrm{CH}_{3} \mathrm{NH}_{3} \mathrm{PbI}_{3}$ crystal wafer ${ }^{[57]}$
发速度和溶液浓度可以控制晶体生长速度和尺寸。 如图 7(a)和(b)所示, Bakr 等 ${ }^{[39]}$ 用这种方法成功制备 出 $\mathrm{CH}_{3} \mathrm{NH}_{3} \mathrm{PbI}_{3}$ 单晶。

\subsection{2 乙腈辅助结晶}

2016 年, Fan 等 ${ }^{[44]}$ 用乙腈辅助结晶首次在 $70^{\circ} \mathrm{C}$ 制备出厘米级 $\mathrm{CH}_{3} \mathrm{NH}_{3} \mathrm{PbI}_{3}$ 单晶，他们在实验中发 现 $\gamma$-丁内酯溶液中加入适量乙腈后会促进 $\mathrm{CH}_{3} \mathrm{NH}_{3} \mathrm{I}$ 和 $\mathrm{PbI}_{2}$ 加速溶解并改变 $\mathrm{CH}_{3} \mathrm{NH}_{3} \mathrm{PbI}_{3}$ 溶解度随温度 变化曲线，使 $\mathrm{CH}_{3} \mathrm{NH}_{3} \mathrm{PbI}_{3}$ 在 $70^{\circ} \mathrm{C}$ 就可以结晶析出。 这种方法在 $\gamma$-丁内酯作溶剂的溶液体系中首次在相 对较低温度下实现厘米级 $\mathrm{CH}_{3} \mathrm{NH}_{3} \mathrm{PbI}_{3}$ 单晶快速生 长, 加入乙腈后 $\mathrm{CH}_{3} \mathrm{NH}_{3} \mathrm{PbI}_{3}$ 温度溶解度曲线和最 后得到的单晶体如图 7(c)和(d)所示。

\subsection{3 氯苯(CB) 辅助结晶}

随后 $\mathrm{Liu}$ 等 ${ }^{[45]}$ 发现氯苯也能改变 $\mathrm{CH}_{3} \mathrm{NH}_{3} \mathrm{PbI}_{3}$ 在 $\gamma$-丁内酯溶液中的溶解度, 如图 7(e)所示, 加入 一定量氯苯后的 $\mathrm{CH}_{3} \mathrm{NH}_{3} \mathrm{PbI}_{3}$ 晶体溶液在 $30^{\circ} \mathrm{C}$ 左右 即可达到饱和, 在 $60^{\circ} \mathrm{C}$ 析出约 $50 \%$, 成功制备出厘 (a)

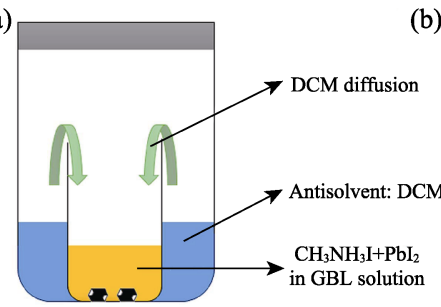

(c)

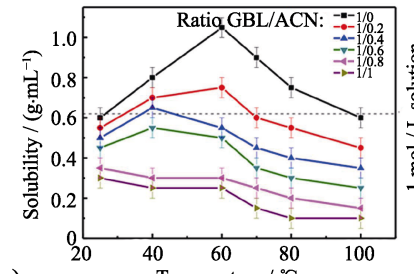

(e)

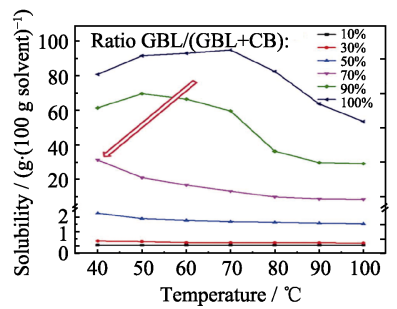

(d)

(f) (b)

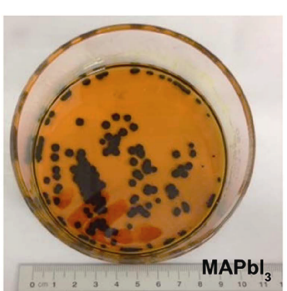

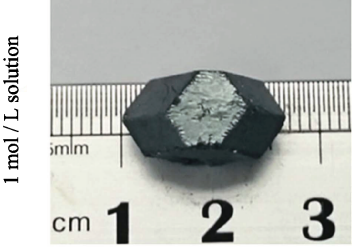

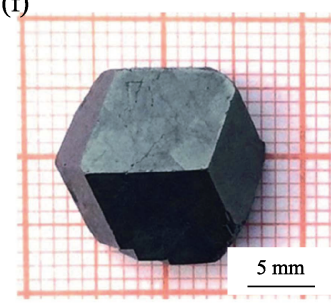

图 7 溶剂辅助法结晶(a) (b)二氯甲烷辅助结晶及晶体产物 照片 ${ }^{[39]}$; (c) (d) $\mathrm{CH}_{3} \mathrm{NH}_{3} \mathrm{PbI}_{3}$ 在 $\mathrm{GBL} / \mathrm{ACN}$ 混合溶剂溶解度曲 线及单晶实物照片 ${ }^{[44]}$; (e) (f) $\mathrm{CH}_{3} \mathrm{NH}_{3} \mathrm{PbI}_{3}$ 在 $\mathrm{GBL} / \mathrm{CB}$ 混合 溶剂溶解度曲线及单晶实物照片 ${ }^{[45]}$

Fig. 7 Schematic diagram of solvent assisted crystallization (SAC)

(a)-(b) Crystallization process of DCM assisted and images of as-prepared $\mathrm{CH}_{3} \mathrm{NH}_{3} \mathrm{PbI}_{3}$ crystals ${ }^{[39]}$; (c)-(d) Solubility of $\mathrm{CH}_{3} \mathrm{NH}_{3} \mathrm{PbI}_{3}$ at different temperatures in mixed-solvent of GBL and $\mathrm{ACN}$, and image of as-prepared $\mathrm{CH}_{3} \mathrm{NH}_{3} \mathrm{PbI}_{3}$ single crystal ${ }^{[44]}$; (e)-(f) Solubility of $\mathrm{CH}_{3} \mathrm{NH}_{3} \mathrm{PbI}_{3}$ at different temperatures in mixed-solvent of GBL and $\mathrm{CB}$, and image of as-prepared $\mathrm{CH}_{3} \mathrm{NH}_{3} \mathrm{PbI}_{3}$ single crystal ${ }^{[45]}$ 
米级单晶, 如图 7(f)所示。

与绝大多数钙钛矿晶体一样, $\mathrm{CH}_{3} \mathrm{NH}_{3} \mathrm{PbI}_{3}$ 晶体 结构也会随温度发生晶系转变。 $\mathrm{CH}_{3} \mathrm{NH}_{3} \mathrm{PbI}_{3}$ 晶体正 交晶系与四方晶系、四方晶系与立方晶系之间转变 温度分别为 -111.0 和 $54.3^{\circ} \mathrm{C}^{[59]}$, 这也意味着在溶液 高温时制备的 $\mathrm{CH}_{3} \mathrm{NH}_{3} \mathrm{PbI}_{3}$ 晶体通常为立方晶系, 置于室温时逐渐转变为四方晶系, 这一过程虽然缓 慢却对钻钛矿晶体有极重要影响。上述几种在较高 温度下制备的 $\mathrm{CH}_{3} \mathrm{NH}_{3} \mathrm{PbI}_{3}$ 晶体室温时由 $\mathrm{X}$ 射线衍 射图谱可以看出都属于四方晶系, 表明 $\mathrm{CH}_{3} \mathrm{NH}_{3} \mathrm{PbI}_{3}$ 晶体在室温下发生了晶系转变, 晶系转变带来的体 积变化虽然微小却极容易导致晶体不稳定; 而溶剂 辅助能在较低温度实现晶体生长, 减少晶系转变带 来的变化甚至不发生晶系转变, 这也是溶剂辅助结 晶一大优势, 比如氯苯辅助结晶在稍高于晶系转变 温度 $\left(60^{\circ} \mathrm{C}\right)$ 制备的 $\mathrm{CH}_{3} \mathrm{NH}_{3} \mathrm{PbI}_{3}$ 单晶在室温时仍可 保持立方晶系, 避免了晶系转变带来的体积变化从 而使晶体稳定性更好, 为突破限制 $\mathrm{CH}_{3} \mathrm{NH}_{3} \mathrm{PbI}_{3}$ 单 晶材料广泛应用的稳定性问题迈出了坚实一步。

除了生长大尺寸的高质量 $\mathrm{CH}_{3} \mathrm{NH}_{3} \mathrm{PbI}_{3}$ 单晶外, Lian 等 ${ }^{[60]}$ 在 $\mathrm{CH}_{3} \mathrm{NH}_{3} \mathrm{I} / \mathrm{Pb}(\mathrm{AC})_{2} \cdot 3 \mathrm{H}_{2} \mathrm{O} / \mathrm{HI}$ 溶液体系中 引入氯元素采用底部籽晶法成功制备出厘米级氯掺 杂的 $\mathrm{CH}_{3} \mathrm{NH}_{3} \mathrm{PbI}_{3}(\mathrm{Cl})$ 单晶。元素分析发现 $\mathrm{CH}_{3} \mathrm{NH}_{3}$ $\mathrm{PbI}_{3}(\mathrm{Cl})$ 单晶中含有少量氯, 氯元素的掺杂能明显提 高晶体结晶质量 ${ }^{[61]}$ 。作为衡量晶体结晶质量的重要参 数 $\mathrm{X}$ 射线摇摆曲线半高峰宽 $\mathrm{FWHM}, \mathrm{CH}_{3} \mathrm{NH}_{3} \mathrm{PbI}_{3}(\mathrm{Cl})$ 单晶半高峰宽只有 20 角秒, 远低于目前报道 $\mathrm{CH}_{3} \mathrm{NH}_{3} \mathrm{PbI}_{3}$ 单晶的 1388 角秒, 其晶体缺陷密度也 只有 $7.6 \times 10^{8} \mathrm{~cm}^{-3}$, 在一系列测试中都展现出更高
的载流子迁移率和载流子寿命 ${ }^{[60]}$ 。

综上所述, 如表 1 所示, 不同方法所用溶液体 系和结晶温度不同, 钙铁矿单晶生长速度和结晶质 量各有差异, 单晶各项参数也略有差异。在实验中 我们发现降温法生长 $\mathrm{CH}_{3} \mathrm{NH}_{3} \mathrm{PbI}_{3}$ 单晶最容易实现; 升温法和溶剂辅助法都是在 $\gamma$-丁内酯溶剂或 $\gamma$-丁内 酯混合溶剂中生长, 试剂材料的纯度和水含量会直 接影响其溶解度, 配制 $1.2 \mathrm{~mol} \cdot \mathrm{L}^{-1}$ 以上浓度的晶体 生长液逐渐变得比较困难需要花费的时间也更长。 另一方面, 升温法结晶生长速度最快, 数小时就可 以实现毫米甚至厘米级单晶生长, 方便多次重复升 温过程生长大尺寸单晶; 而溶剂辅助结晶则一般是 在相对较低温度下, 在接近钻钛矿晶系转变温度时 结晶, 有利于保持更好的单晶稳定性。关于 $\mathrm{CH}_{3} \mathrm{NH}_{3} \mathrm{PbI}_{3}$ 单晶形状的调控, 适当调整晶体溶液 的配料比和晶体生长方法、采用空间限域限制晶体 生长的方法都是对单晶形状进行控制的有效手 段 ${ }^{[62-63]}$, 能够获得不同形状和尺寸的钙钛矿单晶, 以满足各种光电器件不同需要 ${ }^{[41]}$ 。

\section{4 钙钛矿单晶的应用}

随着太阳能光电器件和钙钛矿单晶制备工艺的 发展, 高质量大尺寸钙钛矿单晶在高能激光 ${ }^{[64]}$ 、光 电探测 ${ }^{[65]} 、 X$ 射线探测 ${ }^{[66]}$ 、半导体发光 ${ }^{[67]}$ 、太阳能 转化 ${ }^{[68-69]}$ 、压电传感 ${ }^{[48]}$ 、光催化分解水产氢 ${ }^{[70]}$ 等方 面必然具有更广泛应用，现阶段已经有越来越多的 研究者注意到钙铁矿单晶的优良光电特性并开始将 其应用到更广泛的领域，如图 8 所示。

表 1 目前各种方法制备的 $\mathrm{CH}_{3} \mathrm{NH}_{3} \mathrm{PbI}_{3}$ 单晶性能比较

Table 1 A summary of properties of $\mathrm{CH}_{3} \mathrm{NH}_{3} \mathrm{PbI}_{3}$ single crystal by different methods

\begin{tabular}{|c|c|c|c|c|c|c|c|c|}
\hline $\begin{array}{l}\text { Growth } \\
\text { method }\end{array}$ & Solvent & $T /{ }^{\circ} \mathrm{C}$ & Size/mm & $\begin{array}{c}\text { Carrier mobility/ } \\
\left(\mathrm{cm}^{2} \cdot \mathrm{V}^{-1} \cdot \mathrm{s}^{-1}\right)\end{array}$ & Trap density $/ \mathrm{cm}^{-3}$ & Bandgap/eV & Crystal system & Ref. \\
\hline \multirow[t]{4}{*}{ STL } & $\mathrm{HI}$ & $65 \rightarrow 40$ & $10 \times 10 \times 8$ & - & - & 1.48 & Tetragonal & [38] \\
\hline & HI & $100 \rightarrow 57$ & $12 \times 12 \times 7$ & - & - & 1.48 & Tetragonal & [42] \\
\hline & HI & $105 \rightarrow 40$ & $20 \times 18 \times 6$ & $167 \pm 35$ & $(1.8 \pm 1.0) \times 10^{9}$ & - & Tetragonal & [60] \\
\hline & HI & 75 & $10 \times 3$ & $164 \pm 25$ & $3.6 \times 10^{10}$ & - & Tetragonal & [40] \\
\hline \multirow[t]{4}{*}{ ITC } & GBL & $60 \rightarrow 110$ & 5.8 & $67.2 \pm 7.3$ & $(1.4 \pm 0.2) \times 10^{10}$ & 1.51 & Tetragonal & [41] \\
\hline & GBL & $50 \rightarrow 100$ & $71 \times 54 \times 39$ & 34 & $4.8 \times 10^{10}$ & 1.53 & Tetragonal & [43] \\
\hline & GBL & - & $113 \times 58 \times 52$ & 41 & $2.1 \times 10^{8}$ & - & Tetragonal & [55] \\
\hline & GBL & $60 \rightarrow 110$ & $\begin{array}{l}150 \mu \mathrm{m} \text { in } \\
\text { thickness }\end{array}$ & 39.6 & $6.0 \times 10^{8}$ & 1.45 & Tetragonal & {$[56]$} \\
\hline \multirow[t]{3}{*}{$\mathrm{SAC}$} & GBL/DCM & $\begin{array}{c}\text { Room } \\
\text { temperature }\end{array}$ & Millimeters & 2.5 & $(3.3 \pm 0.3) \times 10^{10}$ & 1.51 & Tetragonal & [39] \\
\hline & GBL/ACN & $60 \rightarrow 70$ & 17 & - & - & - & Tetragonal & [44] \\
\hline & $\mathrm{GBL} / \mathrm{CB}$ & $30 \rightarrow 60$ & $15 \times 15 \times 10$ & - & - & - & Cubic & [45] \\
\hline
\end{tabular}




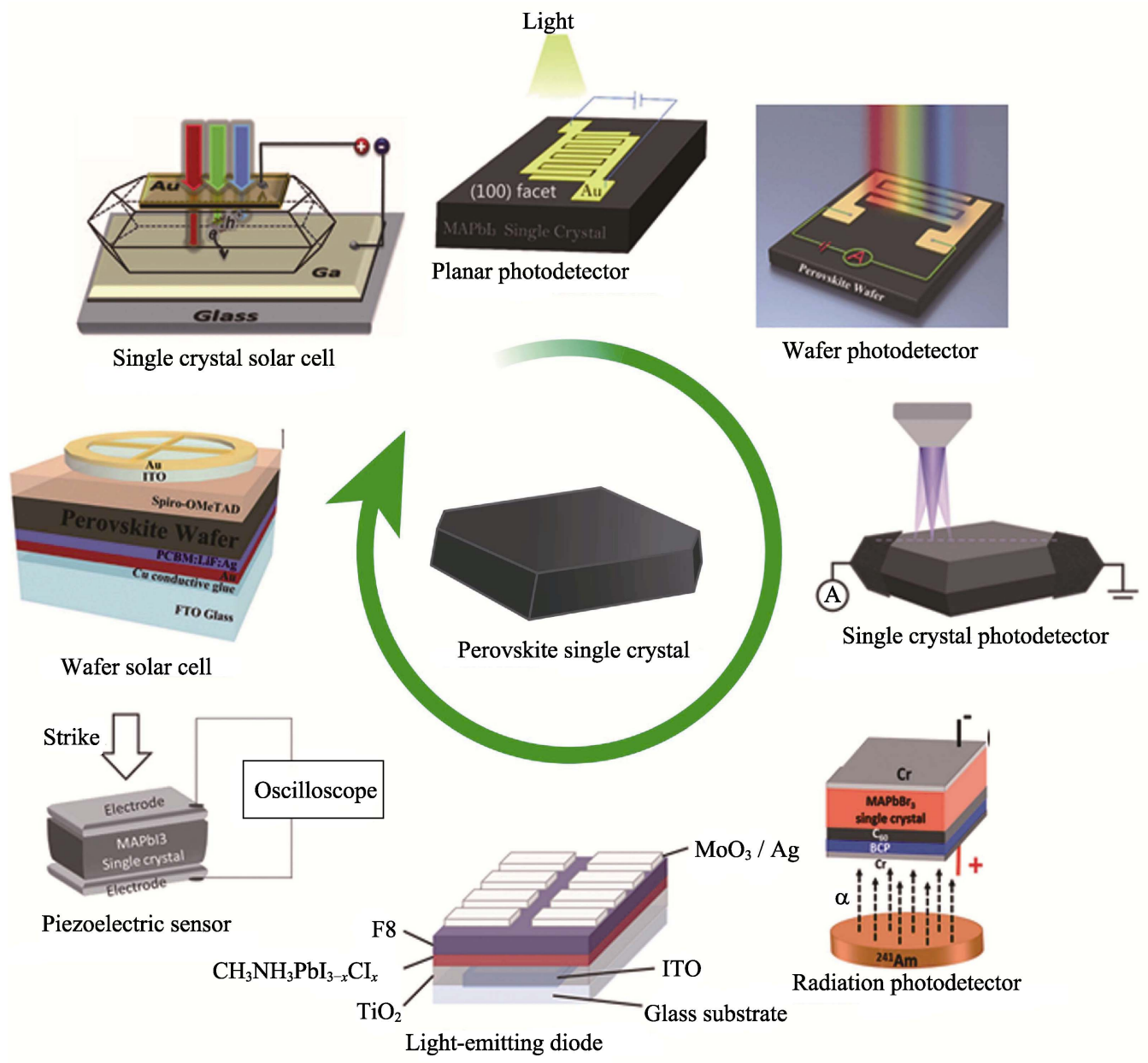

图 8 钲钛矿单晶材料的器件应用 $[40,42,48,56-57,67,71-72]$

Fig. 8 Optoelectronic device applications of perovskite single crystals ${ }^{[40,42,48,56-57,67,71-72]}$

自钙钛矿材料发展以来, 光电探测一直是 $\mathrm{CH}_{3} \mathrm{NH}_{3} \mathrm{PbI}_{3}$ 及其他钙钛矿材料应用最多的领域。光 电探测器可以将光信号转化为电信号, 灵敏度高、 响应速度快的光电探测器在许多方面都具有重要应 用。对光电探测器来说, 响应率 $R$ 和外量子效率 EQE 是衡量其性能好坏的重要指标。利用钙钛矿单 晶载流子扩散距离长和缺陷密度低的特性, Sun 课 题组 ${ }^{[42]}$ 在 $\mathrm{CH}_{3} \mathrm{NH}_{3} \mathrm{PbI}_{3}$ 单晶基础上成功设计钲钛矿 单晶光电探测器, 与薄膜多晶同类探测器相比, 该 单晶探测器具有更好的稳定性、更宽的响应区间、 更快的反应速度、更高的响应率 $R$ 以及外量子效率 $\mathrm{EQE}$, 综合性能全面优于薄膜多晶探测器。Ding 等 ${ }^{[63]}$ 取 $\mathrm{CH}_{3} \mathrm{NH}_{3} \mathrm{PbI}_{3}$ 单晶生长缓慢的 [100] 晶面设计单晶 光电探测器, 晶体生长缓慢通常能比较好地保证结 晶质量并降低晶体缺陷密度, 因此该探测器展现出 非常好的光电特性, 在 $780 \mathrm{~nm}$ 光照下响应率 $R$ 达到 $2.531 \mathrm{~A} \cdot \mathrm{W}^{-1}$, 外量子效率 EQE 达到 $396.20 \%$, 明显 好于 $\mathrm{GaN} 、 \mathrm{GaAs} 、 \mathrm{GaP}$ 等材料设计的光电探测器。 在太阳能电池领域, 一般情况下基于块状单晶
材料制备的太阳能电池由于缺少条件优化和界面调 控, 很难实现高转化效率, Huang 课题组 ${ }^{[40]}$ 首次用 $\mathrm{CH}_{3} \mathrm{NH}_{3} \mathrm{PbI}_{3}$ 单晶作吸光材料设计出钙铁矿单晶太 阳能电池，在没有任何优化的条件下该太阳能电池 短路电流达到 $33.0 \mathrm{~mA} \cdot \mathrm{cm}^{-2}$, 比同类薄膜多晶太阳 能电池提高 $20 \%$ 。随后, Huang 课题组 ${ }^{[48]}$ 又发现 $\mathrm{CH}_{3} \mathrm{NH}_{3} \mathrm{PbI}_{3}$ 单晶材料具有很强的压电效应，沿 [001] 晶面方向压电系数可以达到 $2.7 \mathrm{pm} \cdot \mathrm{V}^{-1}$, 在此基础 上设计制备的横向结构电池 $\mathrm{Au} / \mathrm{CH}_{3} \mathrm{NH}_{3} \mathrm{PbI}_{3} / \mathrm{Au}$ 在 $170 \mathrm{~K}$ 时光电转换效率可达到 $5.36 \%$, 开路电压 $V_{\mathrm{oc}}$ 和短路电流 $J_{\mathrm{sc}}$ 相比同类型的横向薄膜太阳能电池 都有了很大提升。

高能射线探测器可以探测 $X$ 射线、 $\gamma$ 射线等高 能射线并产生电信号, 多应用于安全监测、医学成 像、工业材料检测等方面。对于高能射线探测器来 说，材料载流子迁移率 $\mu$ 和寿命 $\tau$ 是提高探测灵敏 度的重要因素, 而材料组成原子序数 $\mathrm{Z}$ 是 $\mathrm{X}$ 射线衰 减速度的关键 ( $\mathrm{X}$ 射线衰减系数 $\alpha \propto Z^{4} / E^{3}, E$ 为 $\mathrm{X}$ 射线光子能量); 钻钛矿材料本身优良的光电特性 
加上组成元素中 $\mathrm{Pb} 、 \mathrm{I} 、 \mathrm{Br}$ 原子序数较高, 使得钻钛矿 晶体成为 $X$ 射线探测的理想材料。Cao 和 Huang 等 ${ }^{[66]}$ 利用培养出的 $\mathrm{CH}_{3} \mathrm{NH}_{3} \mathrm{PbBr}_{3}$ 大单晶设计出 $\mathrm{X}$ 射线 单晶探测器, 其 $\mu \tau$ (载流子迁移率和载流子寿命乘 积)可达到 $1.2 \times 10^{-2} \mathrm{~cm}^{2} \cdot \mathrm{V}^{-1}$, 与薄膜多晶同类探测 器相比极大地提高了探测灵敏度。实验还发现钙钛 矿晶体缺陷密度是影响探测器性能的重要因素, 降 低晶体表面缺陷有望实现更好的器件性能。不久后, 该课题组 ${ }^{[71]}$ 又在 $\mathrm{CH}_{3} \mathrm{NH}_{3} \mathrm{PbBr}_{3}$ 单晶基础上设计制 备了辐射探测器用以探测带电离子, 经过测试证明 $\mathrm{CH}_{3} \mathrm{NH}_{3} \mathrm{PbBr}_{3}$ 单晶探测器能够用来探测 $\alpha$ 粒子, 其 $\mu \tau$ 可达到 $(0.4 \sim 1.6) \times 10^{-3} \mathrm{~cm}^{2} \cdot \mathrm{V}^{-1}$, 取得了非常不错 的探测效果。 $\mathrm{Zhu}$ 课题组 ${ }^{[73]}$ 基于 $\mathrm{CH}_{3} \mathrm{NH}_{3} \mathrm{PbI}_{3}$ 单晶 成功设计出可见光及 $X$ 射线两用探测器, 取得了良 好的探测效果及器件稳定性。除了将培养出的块状 单晶直接用于设计制备各种光电器件, Liu 课题组与 LONGI 单晶硅公司合作 ${ }^{[55-56]}$ 利用单晶硅线切割技 术成功将大尺寸块状 $\mathrm{CH}_{3} \mathrm{NH}_{3} \mathrm{PbI}_{3}$ 单晶切割成厚度 可调的单晶薄片, 切割后得到的 $\mathrm{CH}_{3} \mathrm{NH}_{3} \mathrm{PbI}_{3}$ 单晶 片保持了块状单晶良好的结晶质量和光电特性, 用 于制备太阳能电池、光电探测器等器件都取得了非 常不错的效果, 这一技术进一步拓展了钙钛矿单晶 材料在光电器件应用领域。

\section{5 总结与展望}

众多研究表明, 钙钛矿单晶具有极低的缺陷密 度和极少的界面缺陷, 这正是单晶材料具有比多晶 薄膜材料更好光电性能的根本原因之一 $[38-39,47,58,74]$; 而且单晶材料的热稳定性和空气稳定性相对更好, 基于钙钛矿单晶材料有利于设计性能更稳定的光电 器件, 也有利于钙钛矿材料固有的物质特性研究。

随着器件制备和钙钛矿单晶生长技术的发展, 未来以 $\mathrm{CH}_{3} \mathrm{NH}_{3} \mathrm{PbI}_{3}$ 单晶为代表的钙钛矿单晶材料 必定会在物质发光、光电转换、光电探测等方面具 有更广泛应用, 迫切需要各种形貌的高质量钙钛矿 单晶材料。然而目前关于钙钛矿单晶材料制备方法 及光电性能的深入研究还相对较少, 还有许多问题 亟需研究者去探索解决, 例如仍不清楚钙钛矿材料 缺陷密度、载流子扩散距离和材料本身光电性能之 间的内在关系和作用机理, 也不清楚不同方法生长 培养出的单晶之间是否存在性能差异。关于钙钛矿 单晶高效生长方法及其光电特性、原理的探索需要 更多研究者的共同努力, 探索生长制备钙钛矿单晶 材料更高效的方法和工艺, 加深对材料本身特性和 器件性能的研究理解, 寻找进一步提高钙钛矿材料
稳定性的途径, 为钻钛矿材料应用和器件设计扫清 障碍, 进一步推动钙钛矿太阳能电池的快速发展。

\section{参考文献:}

[1] KOJIMA A, TESHIMA K, SHIRAI Y, et al. Organometal halide perovskites as visible-light sensitizers for photovoltaic cells. $J$. Am. Chem. Soc., 2009, 131(17): 6050-6051.

[2] YANG W S, PARK B W, JUNG E H, et al. Iodide management in formamidinium-lead-halide-based perovskite layers for efficient solar cells. Science, 2017, 356(6345): 1376-1379.

[3] http://www.nrel.gov/ncpv/images/efficien-cy_chart.jpg.

[4] WEBER D. $\mathrm{CH}_{3} \mathrm{NH}_{3} \mathrm{PbX}_{3}$, a $\mathrm{Pb}$ (II)-system with cubic perovskite structure. Z. Naturforsch., B: Anorg. Chem., Org. Chem., 1978, 33: 1443-1445.

[5] MITZI D B. Templating and structural engineering in organicinorganic perovskites. J. Chem. Soc., Dalton Trans., 2001, 1: 1-12.

[6] SIDEY V. On the effective ionic radii for ammonium. Acta Crystallogr., Sect. B: Struct. Sci., 2016, 72: 626-633.

[7] NIE W, TSAI H, ASADPOUR R, et al. High-efficiency solutionprocessed perovskite solar cells with millimeter-scale grains. Science, 2015, 347(6221): 522-525.

[8] LIU C, FAN J, LI H, et al. Highly efficient perovskite solar cells with substantial reduction of lead content. Sci. Rep., 2016, 6: 35705 .

[9] WU Y Z, ISLAM A, YANG X D, et al. Retarding the crystallization of $\mathrm{PbI}_{2}$ for highly reproducible planar-structured perovskite solar cells via sequential deposition. Energy Environ. Sci., 2014, 7(9): 2934-2938.

[10] MEI A Y, LI X, LIU L F, et al. A hole-conductor-free, fully printable mesoscopic perovskite solar cell with high stability. Science, 2014, 345(6194): 295-298.

[11] SHI J, DONG J, LV S, et al. Hole-conductor-free perovskite organic lead iodide heterojunction thin-film solar cells: high efficiency and junction property. Appl. Phys. Lett., 2014, 104(6): 063901.

[12] WU Y Z, YANG X D, CHEN W, et al. Perovskite solar cells with $18.21 \%$ efficiency and area over $1 \mathrm{~cm}^{2}$ fabricated by heterojunction engineering. Nat. Energy, 2016, 1: 16148-1-7.

[13] HU H, YAN K, PENG M, et al. Fiber-shaped perovskite solar cells with 5.3\% efficiency. J. Mater. Chem. A, 2016, 4(10): 3901-3906.

[14] YE T, FU W, WU J, et al. Single-crystalline lead halide perovskite arrays for solar cells. J. Mater. Chem. A, 2016, 4(4): 1214-1217.

[15] YAN K, PENG M, YU X, et al. High-performance perovskite memristor based on methyl ammonium lead halides. J. Mater. Chem. C, 2016, 4(7): 1375-1381.

[16] NIU G, LI W, MENG F, et al. Study on the stability of $\mathrm{CH}_{3} \mathrm{NH}_{3} \mathrm{PbI}_{3}$ films and the effect of post-modification by aluminum oxide in all-solid-state hybrid solar cells. J. Mater. Chem. A, 2013, 2(3): 705-710.

[17] LIU C, DING W, ZHOU X, et al. Efficient and stable perovskite solar cells prepared in ambient air based on surface-modified perovskite layer. J. Phys. Chem. C, 2017, 121(12): 6546-6553.

[18] CHATTERJEE S, PA A J. Introducing $\mathrm{Cu}_{2} \mathrm{O}$ thin films as a hole-transport layer in efficient planar perovskite solar cell structures. J. Phys. Chem. C, 2016, 120(3): 1428-1437.

[19] XU W, YAO X, MENG T, et al. Perovskite hybrid solar cells with a fullerene derivative electron extraction layer. J. Mater. Chem. C, 2017, 5: 4190-4197.

[20] SUN C, WU Z, YIP H L, et al. Amino-functionalized conjugated polymer as an efficient electron transport layer for 
high-performance planar-heterojunction perovskite solar cells. $A d v$. Energy Mater, 2016, 6(5): 1501534.

[21] SU J, CHEN D P, LIN C T. Growth of large $\mathrm{CH}_{3} \mathrm{NH}_{3} \mathrm{PbX}$ (X=I, Br) single crystals in solution. J. Cryst. Growth, 2015, 422: 75-79.

[22] ZHOU H, NIE Z, YIN J, et al. Antisolvent diffusion-induced growth, equilibrium behaviours in aqueous solution and optical properties of $\mathrm{CH}_{3} \mathrm{NH}_{3} \mathrm{PbI}_{3}$ single crystals for photovoltaic applications. RSC Adv., 2015, 5(104): 85344-85349.

[23] RONG Y, TANG Z, ZHAO Y, et al. Solvent engineering towards controlled grain growth in perovskite planar heterojunction solar cells. Nanoscale, 2015, 7(24): 10595-10599.

[24] HUANG J S, SHAO Y C, DONG Q F, et al. Organometal trihalide perovskite single crystals: a next wave of materials for $25 \%$ efficiency photovoltaics and applications beyond? J. Phys. Chem. Lett., 2015, 6(16): 3218-3227.

[25] POGLiTSCH A, WEBER D. Dynamic disorder in methylammoniumtrihalogenoplumbates (II) observed by millimeter-wave spectroscopy. J. Chem. Phys., 1987, 87(11): 6373-6378.

[26] BAIKIE T, FANG Y, KADRO J M, et al. Synthesis and crystal chemistry of the hybrid perovskite $\left(\mathrm{CH}_{3} \mathrm{NH}_{3}\right) \mathrm{PbI}_{3}$ for solid-state sensitised solar cell applications. J. Mater. Chem. A, 2013, 1(18): 5628-5641.

[27] IM J H, LEE C R, LEE J W, et al. 6.5\% Efficient perovskite quantumdot-sensitized solar cell. Nanoscale, 2011, 3(10): 4088-4093.

[28] LEE M M, TEUSCHER J, MIYASAKA T, et al. Efficient hybrid solar cells based on meso-superstructured organometal halide perovskites. Science, 2012, 338(6107): 643-647.

[29] KIM H S, LEE C R, IM J H, et al. Lead iodide perovskite sensitized all-solid-state submicron thin film mesoscopic solar cell with efficiency exceeding 9\%. Sci. Rep., 2012, 2: 591.

[30] BURSHKA J, PELLET N, MOON S J, et al. Sequential deposition as a route to high-performance perovskite-sensitized solar cells. Nature, 2013, 499(7458): 316-319.

[31] KU Z, RONG Y, XU M, et al. Full printable processed mesoscopic $\mathrm{CH}_{3} \mathrm{NH}_{3} \mathrm{PbI}_{3} / \mathrm{TiO}_{2}$ heterojunction solar cells with carbon counter electrode. Sci. Rep., 2013, 3: 3132.

[32] LIU M Z, JOHNSTON M B, SNAITH H J, et al. Efficient planar heterojunction perovskite solar cells by vapour deposition. Nature, 2013, 501(7467): 395-398.

[33] ZHOU H, CHEN Q, LI G, et al. Interface engineering of highly efficient perovskite solar cells. Science, 2014, 345(6196): 542-546.

[34] ZHANG W, PATHAK S, SAKAI N, et al. Enhanced optoelectronic quality of perovskite thin films with hypophosphorous acid for planar heterojunction solar cells. Nat. Commun., 2015, 6: 10030-1-9.

[35] YANG W S, NOH J H, JEON N J, et al. High-performance photovoltaic perovskite layers fabricated through intramolecular exchange. Science, 2015, 348(6240): 1234-1237.

[36] STOUMPOS C C, MALLIAKAS C D, KANATZIDIS M G, et al. Semiconducting tin and lead iodide perovskites with organic cations: phase transitions, high mobilities, and near-infrared photoluminescent properties. Inorg. Chem., 2013, 52(15): 9019-9038.

[37] PISONI A, JACIMOVIC J, BARISIC O S, et al. Ultra-low thermal conductivity in organic-inorganic hybrid perovskite $\mathrm{CH}_{3} \mathrm{NH}_{3} \mathrm{PbI}_{3} . J$. Phys. Chem. Lett., 2014, 5(14): 2488-2492.

[38] DANG Y, LIU Y, SUN Y, et al. Bulk crystal growth of hybrid perovskite material $\mathrm{CH}_{3} \mathrm{NH}_{3} \mathrm{PbI}_{3}$. CrystEngComm, 2015, 17(3): 665-670.

[39] SHI D, ADINOLFI V, COMIN R, et al. Low trap-state density and long carrier diffusion in organolead trihalide perovskite single crystals. Science, 2015, 347(6221): 519-522.

[40] DONG Q, FANG Y, SHAO Y, et al. Electron-hole diffusion lengths $>175 \mu \mathrm{m}$ in solution-grown $\mathrm{CH}_{3} \mathrm{NH}_{3} \mathrm{PbI}_{3}$ single crystals. Science, 2015, 347(6225): 967-970.

[41] SAIDAMINOV M I, ABDELHADY A L, MURALI B, et al. High-quality bulk hybrid perovskite single crystals within minutes by inverse temperature crystallization. Nat. Commun., 2015, 6: 7586-1-6.

[42] LIAN Z, YAN Q, LV Q, et al. High-performance planar-type photodetector on (100) facet of $\mathrm{MAPbI}_{3}$ single crystal. Sci. Rep., 2015, 5: 16563.

[43] LIU Y, YANG Z, CUI D, et al. Two-inch-sized perovskite $\mathrm{CH}_{3} \mathrm{NH}_{3} \mathrm{PbX}_{3}(\mathrm{X}=\mathrm{Cl}, \mathrm{Br}, \mathrm{I})$ crystals: growth and characterization. Adv. Mater, 2015, 27(35): 5176-5183.

[44] KU Z, TIEP N H, WU B, et al. Solvent engineering for fast growth of centimetric high-quality $\mathrm{CH}_{3} \mathrm{NH}_{3} \mathrm{PbI}_{3}$ perovskite single crystals. New J. Chem., 2016, 40(9): 7261-7264.

[45] LUAN M, SONG J, WEI X, et al. Controllable growth of bulk cubic-phase $\mathrm{CH}_{3} \mathrm{NH}_{3} \mathrm{PbI}_{3}$ single crystal with exciting room temperature stability. CrystEngComm, 2016, 18(28): 5257-5261.

[46] LI G. Preparation and Characterization of Organic-inorganic Hybrid Perovskite Materials. Changsha: National University of Defense Technology Bachelor Dissertation, 2016.

[47] XIAO Z, DONG Q, BI C, et al. Solvent annealing of perovskite-induced crystal growth for photovoltaic-device efficiency enhancement. Adv. Mater., 2014, 26(37): 6503-6509.

[48] DONG Q, SONG J, FANG Y, et al. Lateral-structure single-crystal hybrid perovskite solar cells via piezoelectric poling. Adv. Mater, 2016, 28(14): 2816-2821.

[49] ZHOU Y Y, LI C M, WANG Y, et al. Preparation and Characterization of High-quality Perovskite $\mathrm{CH}_{3} \mathrm{NH}_{3} \mathrm{PbX}_{3}(\mathrm{I}, \mathrm{Br})$ Single Crystal. 1st International Conference on New Material and Chemical Industry, SanYa, 2017, 167: 012019.

[50] QIN X, YAO Y, DONG H, et al. Perovskite photodetectors based on $\mathrm{CH}_{3} \mathrm{NH}_{3} \mathrm{PbI}_{3}$ single crystals. Chem. Asian J., 2016, 11(19): 2675-2679.

[51] DANG Y, JU D, WANG L, et al. Recent progress in the synthesis of hybrid halide perovskite single crystals. CrystEngComm, 2016, 18(24): 4476-4484.

[52] LEGUY A M A, HU Y, CAMPOY M, et al. Reversible hydration of $\mathrm{CH}_{3} \mathrm{NH}_{3} \mathrm{PbI}_{3}$ in films, single crystals, and solar cells. Chem. Mater., 2015, 27(9): 3397-3407.

[53] VINCENT B R, ROBERTSON K N, CAMERON T S, et al. Alkylammonium lead halides. Part 1. Isolated $\mathrm{PbI}_{6}{ }^{4-}$ ions in $\left(\mathrm{CH}_{3} \mathrm{NH}_{3}\right)_{4} \mathrm{PbI}_{6} \cdot 2 \mathrm{H}_{2} \mathrm{O}$. Can. J. Chem., 1987, 65: 1042-1046.

[54] KADRO J M, NONOMURA K, GACHET D, et al. Facile route to freestanding $\mathrm{CH}_{3} \mathrm{NH}_{3} \mathrm{PbI}_{3}$ crystals using inverse solubility. Sci. Rep., 2015, 5: 11654.

[55] KATZ E A. High quality large single crystals of metal halide perovskites for optoelectronic applications. Sci. Chi. Chem., 2017, 60(10): 1326-1328.

[56] LIU Y C, REN X D, ZHANG J, et al. 120 millimeter single-crystalline perovskite and wafers: towards viable applications. Sci. Chi. Chem., 2017, 60(10): 1367-1376.

[57] LIU Y, ZHANG Y, YANG Z, et al. Thinness- and shape-controlled growth for ultrathin single-crystalline perovskite wafers for mass production of superior photoelectronic devices. Adv. Mater., 2016, 28(41): 9204-9209.

[58] NAYAK P K, MOORE D T, WENGER B, et al. Mechanism for 
rapid growth of organic-inorganic halide perovskite crystals. Nat. Commun., 2016, 7: 13303.

[59] KAWAMURA Y, MASHIYAMA H, HASEBE, K. structural study on cubic-tetragonal transition of $\mathrm{CH}_{3} \mathrm{NH}_{3} \mathrm{PbI}_{3}$. J. Phys. Soc. Jpn., 2002, 71(7): 1694-1697.

[60] LIAN Z, YAN Q, GAO T, et al. Perovskite $\mathrm{CH}_{3} \mathrm{NH}_{3} \mathrm{PbI}_{3}(\mathrm{Cl})$ single crystals: rapid solution growth, unparalleled crystalline quality, and low trap density toward $108 \mathrm{~cm}^{-3}$. J. Am. Chem. Soc., 2016, 138(30): 9409-9412.

[61] YANG B, KEUM J, OVCHINNIKOVA O S, et al. Deciphering halogen competition in organometallic halide perovskite growth. $J$. Am. Chem. Soc., 2016, 138(15): 5028-5035.

[62] ZHANG Y, HUANG F Q, MI Q X, et al. Preferential facet growth of methylammonium lead halide single crystals promoted by halide coordination. Chem. Lett., 2016, 45(8): 1030-1032.

[63] DING J, DU S, ZHAO Y, et al. High-quality inorganic-organic perovskite $\mathrm{CH}_{3} \mathrm{NH}_{3} \mathrm{PbI}_{3}$ single crystals for photo-detector applications. J. Mater. Sci., 2017, 52(1): 276-284.

[64] XING G, MATHEWS N, LIM S S, et al. Low-temperature solutionprocessed wavelength-tunable perovskites for lasing. Nat. Mater., 2014, 13(5): 476-480.

[65] DOU L, YANG Y, YOU J, et al. Solution-processed hybrid perovskite photodetectors with high detectivity. Nat. Commun., 2014, 5: 5404-1-6.

[66] WEI H, FANG Y, MULLIGAN P, et al. Sensitive X-ray detectors made of methylammonium lead tribromide perovskite single crys- tals. Nature Photon., 2016, 10: 333-339.

[67] TAN Z K, MOGHADDAM R S, LAI M L, et al. Bright light-emitting diodes based on organometal halide perovskite. $\mathrm{Na}$ ture Nanotech., 2014, 9(9): 687-692.

[68] STRANKS S D, EPERON G E, GRANCINI G, et al. Electron-hole diffusion lengths exceeding 1 micrometer in an organometal trihalide perovskite absorber. Science, 2013, 342(6156): 341-344.

[69] KIM H S, MORA-SERO I, GONZALEZ V, et al. Mechanism of carrier accumulation in perovskite thin-absorber solar cells. Nat. Commun., 2013, 4: 2242.

[70] CHEN Y S, MANSER J S, KAMAT P V. All solution-processed lead halide perovskite- $\mathrm{BiVO}_{4}$ tandem assembly for photolytic solar fuels production. J. Am. Chem. Soc., 2015, 137(2): 974-981.

[71] XU Q, WEI H, WEI W, et al. Detection of charged particles with a methylammonium lead tribromide perovskite single crystal. Nucl. Instrum. Methods Phys. Res., Sect. A, 2017, 848: 106-108.

[72] SEMONIN O E, ELBAZ G A, STRAUS D B, et al. Limits of carrier diffusion in n-type and p-type $\mathrm{CH}_{3} \mathrm{NH}_{3} \mathrm{PbI}_{3}$ perovskite single crystals. J. Phys. Chem. Lett., 2016, 7(17): 3510-3518.

[73] WANGYANG P H, SUN H, ZHU X H, et al. Solution-processable methyl ammonium lead iodide single crystal photodetectors for visible light and X-ray. Phys. Status Solidi A, 2017, 214(11): 1700538-1-5.

[74] DING J, YAN Q F. Progress in organic-inorganic hybrid halide perovskite single crystal: growth techniques and applications. Sci. Chi. Mater., 2017, 60: 1063-1078. 